\title{
Prospective observational study of the endotracheal intubation complications in Emergency Department
}

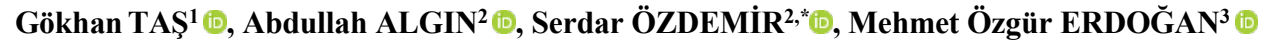 \\ ${ }^{1}$ Department of Emergency Medicine, Sakarya University Training and Research Hospital, Sakarya, Turkey \\ ${ }^{2}$ Department of Emergency Medicine, University of Health Sciences Umraniye Training and Research Hospital, Istanbul, Turkey \\ ${ }^{3}$ Department of Emergency Medicine, Bahcesehir University, Istanbul, Turkey
}

\begin{abstract}
\begin{tabular}{ccccc}
\hline Received: 01.03 .2021 & $\bullet$ & Accepted/Published Online: 14.03 .2021 & $\bullet$ & Final Version: 30.08 .2021 \\
\hline
\end{tabular}
\section{Abstract}

Endotracheal intubation is the gold standard intervention for emergency airway management. Complications related to endotracheal intubation are numerous and frequent. Complications were identified as being related to endotracheal intubation in our study: hypoxia, hypotension, dysrhythmia, cardiac arrest, hypertension, tachycardia, bradycardia, regurgitation and aspiration of stomach contents, endobronchial intubation, and incorrect positioning of the endotracheal tube in either the esophagus or hypopharynx. The study included 186 patients that were over 18 and intubated. The complication rate associated with endotracheal intubation was found to be over 50\%. Patients included in our prospective, observational study were all initially evaluated in our ED. A survey was filled out at a time as soon as possible after intubation to record the personnel in charge of intubation, details of the procedure, and hemodynamic changes and complications. Our study found that the following factors were associated with increased rates of complication in intubated patients: history of acute renal failure, history of cancer, GCS $<8$, midazolam use during intubation, history of trauma, crash intubation, history of shock, history of cardiac arrest, resident with $<1$ year of experience carrying out the intubation, residents with $2+$ years of experience and specialists carrying out the intubation, history of respiratory failure, and patient age $<65$. To better understand which patients were likely to be affected by complications associated with intubation, as well as to understand which precautions to take, this study aims to investigate the aggravating factors and complication rates of endotracheal intubation.
\end{abstract}

Keywords: airway management, intubation, rapid sequence induction and intubation

\section{Introduction}

Endotracheal intubation is frequently utilized in the emergency department (ED) as a life-saving intervention (1). Although alternative strategies may be used in emergencies, endotracheal intubation is the gold standard intervention for emergency airway management (2). In existing studies, the complication rate associated with endotracheal intubation was found to be over 50\% (3). Patients requiring emergency intubation often have underlying conditions which may complicate the procedure. Factors such as the practice of intubating patients prior to premedicating them provide an explanation for this high complication rate (4). Complications related to endotracheal intubation are numerous and frequent. In one study, severe hypoxia and hypotension were reported with rates of $25 \%$ and $10-25 \%$, respectively (5). The causes of a decrease in oxygen saturation can work in isolation or in combination and may include esophageal intubation, vomiting, aspiration, multiple attempts at intubation, and endobronchial intubation (6). Alongside this, unsuccessful intubation risks many emergency complications such as soft tissue damage, arrhythmia, and/or cardiac arrest (7, 2). Many variables independent of the patient also affect the rate of complications of intubation. The experience level of the doctor carrying out the intubation, selection and dosage of neuromuscular blockers, and treatment prior to induction are all important factors (5).

Despite being a frequently used intervention in emergency airway management, few studies have investigated the factors associated with emergency endotracheal intubation success rates. To better understand which patients were likely to be affected by complications associated with intubation, as well as to understand which precautions to take, this study aims to investigate the aggravating factors and complication rates of endotracheal intubation.

\section{Materials and methods}

The study included 186 patients that were over 18, intubated, and admitted to ED of University of Health Sciences İstanbul Haydarpasa Numune Training and Research Hospital between January 01 and June 30. Patients included in our prospective, observational study were all initially evaluated in our ED. All 
patients were intubated in accordance with Rapid Sequence Intubation [RSI] guidelines.

The University of Health Sciences İstanbul Haydarpasa Numune Training and Research Hospital Ethics Committee approved the study on the $22^{\text {nd }}$ of June 2015 (HNEAH-KAEK 2015/KK/51). The patients' data set was used for follow-up with patients and tracking potential complications. Traditional straight and curved laryngoscope blades were used for intubation. Most patients in need of intubation were intubated using RSI. Patients intubated during cardiopulmonary resuscitation were intubated according to crash intubation guidelines. Vecuronium and rocuronium were used as neuromuscular blocking agents. Etomidate, midazolam, and ketamine were used as sedative-hypnotics. All intubated patients were supervised using heart monitors and automatic, non-invasive blood pressure monitors. All intubated patients' oxygen saturation levels were tracked using pulse oximeters. Before intubation, patients were routinely preoxygenated. Endotracheal intubation success was evaluated using colorimetric end-tidal $\mathrm{CO}_{2}$ detection. To locate the end of the endotracheal tube, chest auscultation was performed. After intubation, chest $\mathrm{X}$-rays were taken.

A survey was filled out at a time as soon as possible after intubation to record the personnel in charge of intubation, details of the procedure, and hemodynamic changes and complications. The following parameters were analyzed: patient age, sex, date of admission, weight, Glasgow Coma Scale (GCS) score at admission, indication for intubation, intubation method, sedative and paralytic medicines administered, prevailing year of medical residency of the doctor carrying out the intubation, comorbid diseases, duration of the intubation procedure, and complications and mortality associated with intubation.

Furthermore, the following complications were identified as being related to endotracheal intubation in our study: hypoxia (defined as less than $80 \%$ oxygen saturation as measured on a pulse oximeter at any time), hypotension, dysrhythmia, cardiac arrest, hypertension, tachycardia, bradycardia, regurgitation and aspiration of stomach contents, endobronchial intubation, and incorrect positioning of the endotracheal tube in either the esophagus or hypopharynx (defined as either negative end-tidal $\mathrm{CO}_{2}$, no chest sounds on auscultation, or endotracheal tube fogging). Patients whose file was unavailable or inadequately filled in, patients who died before the relevant tests were carried out, and patients transferred to other facilities were not included in the study.

All data was stored using Microsoft Excel 2010 (Microsoft, Redmond, WA, USA). Statistical analysis of the data was carried out using SPSS Statistics for Windows, version 17.0 (SPSS, Inc., Chicago, IL, USA). The threshold for statistical significance used was $\mathrm{p}<0.05$. Definitive statistical assays were carried out using the Student's t-test or Chi-squared test for parametric and nonparametric data, respectively.

\section{Results}

Of patients included in the study, 112 were male while 72 were female. The average age of male and female patients was 73.04 and 70.28, respectively. Altogether, 38 male patients (34\%) and 20 female patients (28\%) experienced complications. Male gender was associated with increased development of complications ( $\mathrm{p}: 0.0419$, as was age under 65 years old $(\mathrm{p}=0.045)$ (Table 1$)$.

Table 1. Sociodemographic characteristics of patients

\begin{tabular}{|l|c|c|c|}
\hline Male & $\begin{array}{c}\text { Patients with } \\
\text { Complications }\end{array}$ & $\begin{array}{c}\text { Total } \\
\text { Patients }\end{array}$ & $\mathbf{p}$ \\
\hline Female & 38 & 112 & 0.0419 \\
\hline$<65$ years old & 20 & 72 & \\
\hline$>\mathbf{6 5}$ years old & 41 & 33 & 0.045 \\
\hline
\end{tabular}

Upon investigation, patients admitted to the study with chronic illnesses were found to suffer from chronic obstructive pulmonary disease, coronary artery disease, hypertension, diabetes mellitus, acute kidney failure, chronic kidney failure, cerebrovascular accidents, congestive heart failure, and cancer. Patients with a history of acute kidney failure, cerebrovascular accidents, or cancer were found to have an increased incidence of intubation-related complications $(p=0.032,0.07,0.002$, respectively) (Table 2).

Table 2. Chronic illnesses and complication development of patients admitted to the study

\begin{tabular}{|l|c|c|c|}
\hline Comorbidities & $\begin{array}{c}\text { Total } \\
\text { Patients }\end{array}$ & $\begin{array}{c}\text { Patients with } \\
\text { Complication }\end{array}$ & p \\
\hline $\begin{array}{l}\text { Chronic Obstructive } \\
\text { Pulmonary Disease }\end{array}$ & 31 & 10 & $>0.05$ \\
\hline $\begin{array}{l}\text { Coronary Artery } \\
\text { Disease }\end{array}$ & 22 & 7 & $>0.05$ \\
\hline Hypertension & 48 & 18 & 0.370 \\
\hline $\begin{array}{l}\text { Diabetes Mellitus } \\
\text { Acute Kidney }\end{array}$ & 33 & 15 & $>0.05$ \\
\hline Failure & 3 & 3 & 0.032 \\
\hline $\begin{array}{l}\text { Chronic Kidney } \\
\text { Failure }\end{array}$ & 14 & 8 & 0.070 \\
\hline $\begin{array}{l}\text { Cerebrovascular } \\
\text { Accident }\end{array}$ & 7 & 1 & 0.0433 \\
\hline $\begin{array}{l}\text { Congestive Heart } \\
\text { Failure }\end{array}$ & 31 & 7 & 0.292 \\
\hline $\begin{array}{l}\text { Cancer } \\
\text { Cirrhosis }\end{array}$ & 12 & 9 & 0.002 \\
\hline
\end{tabular}

The conditions necessitating intubation in patients included in our study were respiratory failure, shock, intoxication, intracranial hemorrhage, stroke, sepsis, trauma, and GCS $\leq 8$. Patients presenting with shock, trauma, or GCS $\leq 8$ were found to have a statistically significant increase in the rate of complications (Table 3 ). 
Table 3. Conditions necessitating intubation

\begin{tabular}{|l|c|c|c|}
\hline Condition & $\begin{array}{c}\text { Total } \\
\text { Patients }\end{array}$ & $\begin{array}{c}\text { Patients with } \\
\text { Complications }\end{array}$ & p \\
\hline $\begin{array}{l}\text { Respiratory } \\
\text { Failure } \\
\text { Shock }\end{array}$ & 73 & 12 & 0.00034 \\
\hline Intoxication & 10 & 7 & 0.00026 \\
\hline $\begin{array}{l}\text { Intracranial } \\
\text { hemorrhage }\end{array}$ & 5 & 1 & 0.173 \\
\hline Sepsis & 15 & 2 & 0.655 \\
\hline Trauma & 6 & 3 & 0.394 \\
\hline GCS $\leq 8$ & 57 & 5 & 0.013 \\
\hline
\end{tabular}

Midazolam and ketamine were used as anesthetic agents while carrying out the RSI. Vecuronium and rocuronium were used as neuromuscular blockers. Upon analysis of the relationship between complication rate and agents used, the use of midazolam and non-drug assisted intubation were both found to be associated with increased complication rates ( $p$ : 0.013 and p: 00008, respectively) (Table 4).

Table 4. Administered anesthetic and neuromuscular agents

\begin{tabular}{|l|c|c|c|}
\hline $\begin{array}{c}\text { Anesthetic/ } \\
\text { Neuromuscular } \\
\text { agents }\end{array}$ & $\begin{array}{c}\text { Total } \\
\text { Patie } \\
\text { nts }\end{array}$ & $\begin{array}{c}\text { Patients with } \\
\text { Complicatio } \\
\text { ns }\end{array}$ & p \\
\hline Midazolam & 67 & 13 & 0.013 \\
\hline Ketamine & 83 & 27 & 0.875 \\
\hline Rocuronium & 3 & 0 & 0.552 \\
\hline Vecuronium & 138 & 40 & 0.152 \\
\hline $\begin{array}{l}\text { Non-drug assisted } \\
\text { intubation }\end{array}$ & 23 & 16 & 0.00008 \\
\hline
\end{tabular}

Complications that occurred during RSI are displayed in Table 5. The three most common complications were, in order, cardiac arrest, hypotension, and hypoxia (Table 5). The relationship between the experience level (in years) of the resident carrying out the procedure and complication rates was investigated. Residents with less than a year of experience and residents with more than two years of experience were each associated with an increased risk of complications in patients (Table 6). The duration of the intubation procedure was not associated with a significantly increased rate of complications (Table 7).

Table 5. Complications observed during intubation

\begin{tabular}{|l|c|}
\hline Total (n:185) & Patients with Complications \\
\hline Cardiac arrest & 22 \\
\hline Hypotension & 21 \\
\hline Hypertension & 0 \\
\hline Bradycardia & 3 \\
\hline Tachycardia & 2 \\
\hline Dysrhythmia & 6 \\
\hline Aspiration & 4 \\
\hline Death & 11 \\
\hline Soft tissue trauma & 3 \\
\hline Difficult Intubation & 4 \\
\hline Hypoxia & 18 \\
\hline
\end{tabular}

Table 6. Relationship between the resident carrying out the procedure's experience in years and complication rate

\begin{tabular}{|c|c|c|c|}
\hline $\begin{array}{c}\text { Experience } \\
\text { (Years) }\end{array}$ & Total Patients & $\begin{array}{c}\text { Patients with } \\
\text { complications }\end{array}$ & $\mathbf{p}$ \\
\hline $0-1$ & 44 & 26 & 0.00003 \\
\hline $1-2$ & 37 & 9 & 0.327 \\
\hline$>2$ & 100 & 23 & 0.0007 \\
\hline
\end{tabular}

Table 7. Relationship between duration of the intubation procedure and complication risk

\begin{tabular}{|c|c|c|c|}
\hline Duration & Total Patients & $\begin{array}{c}\text { Patients with } \\
\text { Complications }\end{array}$ & $\mathbf{p}$ \\
\hline $0-5$ & 112 & 28 & 0.167 \\
\hline $5-30$ & 42 & 11 & 0.453 \\
\hline $30-120$ & 32 & 11 & 0.835 \\
\hline$<120$ & 36 & 9 & 0.426 \\
\hline
\end{tabular}

\section{Discussion}

Due to inadequate preparation of patients in the ED, complications are frequent occurrences. In this study, we aimed to identify these complications and investigate the associated factors to facilitate the development of solutions to reduce the incidence of complications. For this purpose, we prospectively analyzed 186 intubation procedures in the ED. A statistically significant relationship was found between male gender and an increased rate of complications. Similarly, a statistically significant increase in complications was identified in patients under 65 years old.

Intubation-associated complication risk was also found to be significantly increased in patients with respiratory failure. An existing study found respiratory failure to be associated with an increase in the rate of intubation-related complications. Our study replicated these results. In this area, inadequate preoxygenation, hypoxia occurring during intubation, and time pressure on doctors may be causative factors for complications $(8,9)$.

Midazolam is a slow (2-3 minutes without opioid action) and long-acting agent for inducing anesthesia. According to a study by Sagar et al., conventional midazolam dosage was insufficient for use in RSI (10). This is generally due to a fear of associated hypotension. Intravenous midazolam dosage for use in RSI is $0.2-0.3 \mathrm{mg} / \mathrm{kg}$. For a $70 \mathrm{~kg}$ patient, this is a $15-$ $20 \mathrm{mg}$ induction dose. Recently, physicians have been dissuaded from using midazolam to induce anesthesia (10). This is due to its association with delayed induction, unpredictable hypotension, and prolonged effects. In this study, midazolam was identified as an important factor that influenced the complication rates of endotracheal intubation. Patients who were administered midazolam in our study experienced a high rate of hypotension. Neither ketamine nor propofol were associated with a significant increase in complication rates. For this reason, ketamin or propofol should be recommended for use in RSI. 
Taş et al. / J Exp Clin Med

Our study identified a statistically significant increase in intubation-associated complications when non-drug assisted intubation was applied. Crash intubation is applied in patients undergoing cardiopulmonary resuscitation. Due to the urgency with which this group of patients must be intubated, an increased rate of complications is observed. According to one study, the most frequent complications in this group of patients were soft tissue injuries, hypotension, and esophageal intubation. In this study, crash intubation was associated with a higher risk of tissue damage when compared to RSI. Another available study suggests that crash intubation increases the risk of complications including hypotension, repeated intubation attempts, esophageal intubation, cardiac arrest, and oxygen desaturation (11). Our study identified an association between increased intubation-related complication rate and crash intubation. Cardiac arrest, oxygen desaturation, and hypotension rates were significantly increased.

Furthermore, our study found a significantly increased rate of complications if the intubations were performed by residents in their first year of specialty training. Similarly, increased rates of complications were associated with intubations performed by those with more than two years of experience, a category that includes both residents and fully trained specialists. Intubation procedures are lifesaving, extremely important procedures that must be performed with utmost care. Residents with inadequate experience may cause tissue damage, repeatedly fail to intubate patients, or increase the risk of oxygen desaturation prolonging the interval before successful intubation. Difficult intubations were associated with residents that have completed their second year of training and fully trained specialists. Difficult intubations were also, predictably, associated with high complication rates. Due to this, these intubations may be better categorized as distinct from RSI. One study concluded that residents that have completed their first year of training had a 50\% success rate in intubating patients compared to a $70 \%$ success rate for residents in their third year of training. Similarly, a past study found that intubation success rates were directly correlated with resident or specialist experience (9). Our study produced similar results.

Our study found that the following factors were associated with increased rates of complication in intubated patients: history of acute renal failure, history of cancer, GCS $<8$, midazolam use during intubation, history of trauma, crash intubation, history of shock, history of cardiac arrest, resident with $<1$ year of experience carrying out the intubation, residents with $2+$ years of experience and specialists carrying out the intubation, history of respiratory failure, and patient age <65. Our patients experienced the following complications: hypoxia, dysrhythmia, cardiac arrest, soft tissue trauma, unsuccessful intubation, tachycardia, bradycardia, and aspiration. Paying extra attention to the above factors may result in reduced complication rates.

\section{Conflict of interest}

There is no conflict of interest between authors.

\section{Funding}

No funding was received for this study.

\section{References}

1. Sakles JC, Deacon JM, Bair AE, Keim SM, Panacek EA. Delayed complications of emergency airway management: a study of 533 emergency department intubations. West J Emerg Med. 2008; 9(4):190-4. PMID: 19561743.

2. Bernhard M, Becker TK, Gries A, Knapp J, Wenzel V. The First Shot Is Often the Best Shot: First-Pass Intubation Success in Emergency Airway Management. Anesth Analg. 2015; 121(5):1389-93. doi: 10.1213/ANE.0000000000000891.

3. Griesdale DE, Bosma TL, Kurth $T$, Isac G, Chittock DR. Complications of endotracheal intubation in the critically ill. Intensive Care Med. 2008; 34(10):1835-42. doi: 10.1007/s00134008-1205-6.

4. Fogg T, Annesley N, Hitos K, Vassiliadis J. Prospective observational study of the practice of endotracheal intubation in the emergency department of a tertiary hospital in Sydney, Australia. Emerg Med Australas. 2012; 24(6):617-24. doi: 10.1111/1742-6723.12005.

5. Simpson GD, Ross MJ, McKeown DW, Ray DC. Tracheal intubation in the critically ill: a multi-centre national study of practice and complications. Br J Anaesth. 2012; 108(5):792-9. doi: 10.1093/bja/aer504.

6. Mort TC. Complications of emergency tracheal intubation: immediate airway-related consequences: part II. J Intensive Care Med. 2007; 22(4):208-15. doi: 10.1177/0885066607301359.

7. Kim WY, Kwak MK, Ko BS, Yoon JC, Sohn CH, Lim KS, et al. Factors associated with the occurrence of cardiac arrest after emergency tracheal intubation in the emergency department. PLoS One. 2014; 9(11): el12779. doi: 10.1371/journal.pone.0112779.

8. Dyett JF, Moser MS, Tobin AE. Prospective observational study of emergency airway management in the critical care environment of a tertiary hospital in Melbourne. Anaesth Intensive Care. 2015; 43(5):577-86. doi: $10.1177 / 0310057 X 1504300505$.

9. Caltık A, "Çocuk yoğun bakımda hastalarında endotrekeal entübasyon deneyimleri," Araştırma yazısı, Ankara üniversitesi Tıp Fakültesi Mecmuası. 2006; 59: 93-97.

10. Sagarin MJ, Barton ED, Chng YM, Walls RM. National Emergency Airway Registry Investigators. Airway management by US and Canadian emergency medicine residents: A multicenter analysis of more than 6,000 endotracheal intubation attempts. Ann Emerg Med. 2005; 46(4):328-36. doi: 10.1016/j.annemergmed.2005.01.009.

11. Nasir S, Shehbaz L, Raza H, Basar S. Endotracheal intubation procedures; performed at accident and emergency department at Civil Hospital Karachi Pakistan, Professional. Med J. 2015; 22 (11): 1509-13. 